\title{
Pressure Surge Dependence on Valve Operations in a Pipeline Loading System
}

\author{
Barinaadaa Thaddeus Lebele-Alawa, Felix Ezekiel Oparadike \\ Department of Mechanical Engineering, Rivers State University of Science and Technology, Port Harcourt, \\ Nigeria \\ Email: lebele-alawa.thaddeus@ust.edu.ng
}

Received 19 May 2015; accepted 20 June 2015; published 23 June 2015

Copyright (C) 2015 by authors and Scientific Research Publishing Inc.

This work is licensed under the Creative Commons Attribution International License (CC BY). http://creativecommons.org/licenses/by/4.0/

(c) (i) Open Access

\section{Abstract}

This paper discusses the influence of valve operations on pressure surge in a pipeline. The valve is a protective type which remains open in a pipeline loading system during normal operation but shut down the system when there is an emergency such as storm. The data for the study were obtained from measurements at Agbada 1 flow station as well as log sheets. Also, calculations were made using existing and derived formulas to obtain the values of Crude Oil and Pipe parameters that could not be measured directly or derived from data or log sheets. Surge analysis was carried out on the pipeline system to ascertain changes in pressure and flow rates along the pipeline following valve shut down at any time using developed pressure and flow equations. The results of the simulation analysis showed remarkable changes in the fluid pressure and flow rates along the pipe on shut down at any time. The pipeline recorded the highest pressure of 37.4 bar against initial pressure of 25 bar at length $6000 \mathrm{~m}$ in 1.5 second valve closure. There is also remarkable pressure drop along the pipe capable of reducing the crude oil pressure below its vapour pressure. The flow is turbulent even before valve operation with Reynolds number as high as 57024.53. The model equations compute changes in pressure and flow rates at different points in a pipeline installed with emergency-relief coupling valve. This enables point of extreme and low pressure to be detected accurately in a pipeline which guides the engineer while positioning surge suppression devices which cushion the effects of pressure surge in any pipeline.

\section{Keywords}

Pressure Surge, Valve, Pipeline, Crude Oil

\section{Introduction}

This paper addresses the issue of pressure surge arising from transmission of fluid (crude oil) in pipe following 
the instantaneous closure of an emergency relief coupling valve (ERV) installed in a pipeline system. The pressure changes at different points on the pipe arising from the shutdown of the ERV when transmitting a given quantity of crude oil in a given pipe diameter over given pipe length is to be determined with the associated closure time $t$ given. This valve serves as a protection valve and it is always open during normal operations of the system. It is installed to close when there is an event such as storm that can damage pipe machines which leads to outbreak of fire or crude oil leakage. When this valve closes instantaneously, that is at $t=0$, the initial head rises to infinity. However, in practice, it is not possible to close this valve instantaneously as it always takes some time.

Usually, most pipelines have installed surge suppression devices. In this case, surge suppression, to an extent is taken care of. What if these suppression devices fail or there is an installation failure? It means the whole system would have problem if the ERV eventually shut down. But this shut down to safeguard the system, leads to a fluctuating pressure in the system that threaten the system make up. This pressure changes is computed using developed model. Also of interest is the hydraulic force developed in the bend as a result of the ERV closure at time $t$.

Stone [1] carried out the analysis of avoiding pressure surge in pipeline system. According to the research, there is one prime requirement to avoid pressure surge damage to piping and pipeline. This has to do with bearing in mind that there is likely to be surge in a pipeline system either by measurement or by engineering analysis. The research concluded that damages arising from surge events are; catastrophic failure of the pipeline system or equipment and fatigue failure of the pipeline supports, instrumentation, equipment and components. Hence, pipe work can be designed to withstand the damaging effects of pressure surges. This becomes necessary where conventional means of mitigating surge pressures cannot be employed such as when handling radioactive, highly corrosive or lethal fluids, where no fluid is allowed to escape. The research concluded that increase in pipe wall thickness, flange rating and pipe supports can be designed to prevent catastrophic failure. In order to prevent an increase in surge fatigue damage, devices such as variable speed drives for pumps and slow closing valves should be considered. Also rerouting of pipelines can avoid a profile that is conducive to column separation. For a particular pipeline, it may be possible to use a thermoplastic or GRP material rather than a ferrous pipe material. This applies to low head pipelines found in the mining water and waste water industry where high temperatures do not occur. Therefore, the reduced modulus, results in a reduced celerity or wave speed. The modulus is the prime variable in establishing the celerity.

Pressure surges in fluid systems often lead to pipe damages [2] [3]. They are caused by an abrupt change in flow speed and can have amplitudes higher than the usual pressure conditions in normal operation. Preventing pressure surges is an important consideration in the design and reliable operation of pipes. The analysis concluded that changes in pipe system such as an increase in through put quantities or a change of operating mode can bring about the danger of pressure surges that may excessively stress the system. The research analyzed entire pipe system with regard to pressure surges. On the basis of its findings, the suggestions for solutions include adjustment of the valve closing times, additional air vessels, and use of bypass valves, ventilation or bleeding valves, Non-return valves and pump fly wheel mass.

Cla-val [4] carried out research on complex pipelines with undulating terrain where column separation in the pipe may occur. Hence, the research stated that detail pipeline profile as well as air valve size and placement when pump stops due to power failure causes down surge wave which travels down the pipe. Low pressure wave is reflected at the pipe end boundary back to the pump with a resulting high pressure spike generated at the pump. This high pressure spike damages the piping. A test was carried out using a standard relief valve. The standard relief valve could not open fast enough to dissipate the excess pressure spike but on testing with cal-val 52-03 surge anticipator valve, it opened on the initial down surge pressure and stays open to dissipate the returning high pressure wave.

Jung, et al. [5] showed in their research that surge modeling is important to safeguard against breaches in distribution system integrity. Several cases were considered in this research. Hence the surge analysis results of the pressure-sensitive demand model were compared with those of pressure-insensitive (constant) demand formulations.

This paper reviews the engineering analysis behind pressure surge propagation in a pipeline system. The analysis is carried out on a $254 \mathrm{~mm}$ pipe of length 6 kilometers from the emergency relief-coupling valve (ERV) installation point. The pipeline carries crude oil whose flow is aided by pumps from a flow station. The pipe terminates at a loading point. The system is made up of two valves namely the normal-shut off valve (NSV) and 
the emergency relief coupling valve (ERV). Of interest to this project is the closure time of the ERV at time, $t$ and the pressure changes which accompanies this closure. The pressure change in the system results to two basic anomalies namely surge pressure and cavitations or column separation. These two anomalies threaten the operation of pipeline system especially pipe machines such as pumps, fittings and also leads to spillage.

\section{Materials and Methods}

Data were collected from direct measurements, log sheets for ten months, and relevant charts and manuals. Some of the pertinent parameters were: crude oil density, pipeline length, pipe diameter, flow rate, flow pressure, pipe roughness size, fittings, viscosity of crude oil, Young's Modulus of the pipe, emergency-relief coupling valve installed closure or shutdown time.

In laminar flow, frictional forces are due to viscous drag and are independent of pipe conditions but in turbulent flow, viscous shear predominates. Total friction is affected by pipe surface roughness. The pipeline under investigation undergoes turbulent flow. Therefore, friction and head losses in the pipe are calculated using the following equations [6]:

$$
\begin{gathered}
H=h_{f}+\text { Losses due to fittings (bends) } \\
H=h_{f}+\frac{k_{1} v^{2}}{2 g}+\frac{k_{2} v^{2}}{2 g} \\
\text { But } h_{f}=f_{m} \frac{l}{d} \cdot \frac{v^{2}}{2 g}
\end{gathered}
$$

The following pressure wave equations for pipe flow were used to evaluate pressure changes due to gradual valve closure by the emergency-relief coupling valve [7]:

Retardation of crude oil (fluid)

$$
=\frac{v-0}{t}=\frac{v}{t}
$$

Force available for producing retardation $=$ mass $\times$ retardation

$$
=\rho A l \times \frac{v}{t}
$$

Force due to pressure wave

$$
=p_{L} \times A
$$

Therefore,

$$
\begin{gathered}
\rho A L \times \frac{v}{t}=P_{L} \times A \\
P_{L}=\frac{\rho L v}{t}
\end{gathered}
$$

But

$$
\begin{aligned}
& V=\frac{Q}{A} \\
& A=\pi \frac{d^{2}}{4}
\end{aligned}
$$

Therefore,

$$
V=\frac{4 Q}{\pi d^{2}}
$$

Therefore, Equation (8) becomes 


$$
P_{L}=\frac{4 \rho L Q}{\pi t d^{2}}
$$

Equation (12) is used to model the pressure change at any point in the pipeline arising from shut down of pipeline by emergency-relief coupling valve (ERV).

The Reynolds number of the fluid following valve closure at time $t$ is deduced using equation below;

$$
\mathrm{Re}=\frac{\rho L d}{\mu} \cdot \frac{1}{t} .
$$

The wave speed of the system is calculated using equation below [6]:

$$
C=\sqrt{\frac{\frac{k_{1}}{\rho}}{1+\left[\frac{k_{1} d}{E y t_{h}}\right]}}
$$

Unbalanced hydraulic forces are normally created by pressure surge phenomenon and are particularly dangerous. The following equations are used to calculate the magnitude of hydraulic forces propagated [7]:

Force generated in the 45 degrees elbow or bend;

$$
\begin{gathered}
F_{x}=m\left(V-V_{1} \cos 45^{\circ}\right)+\left(P_{1} A_{1}\right)-P_{2} A_{2} \cos 45^{\circ} \\
F_{y}=m\left(V-V_{1} \sin 45^{\circ}\right)-P_{2} A_{2} \sin 45^{\circ}
\end{gathered}
$$

Force generated in 90 degrees elbow or bend;

$$
\begin{gathered}
F_{x}=m v+\left(P_{1} A_{1}\right) \\
F_{y}=m\left(-V_{1}\right)-P_{2} A_{2} \\
F=\sqrt{F_{x}^{2}+F_{y}^{2}}
\end{gathered}
$$

When the valve (ERV) is shut at time, $t$ the crude oil moving with velocity, $v$, at a temperature, $T$, is brought to rest adiabatically, hence reaching a final temperature, $T_{O}$, when at rest. The flow equation becomes [8] [9]:

$$
\begin{gathered}
C_{p} T+\frac{V^{2}}{2}=C_{p} T_{o} \\
T_{o}=T+\frac{V^{2}}{2 C_{P}}
\end{gathered}
$$

At the valve, the stagnation pressure, $P_{o}$, would be:

$$
P_{o}=P+\frac{\rho V^{2}}{2}
$$

Also, the crude oil would have enthalpy:

$$
H_{o}=h+\frac{V^{2}}{2}
$$

\section{Results and Discussions}

The results are presented in Tables 1-12.

From the results shown above, the flow velocity is $1.12 \mathrm{~m} / \mathrm{s}$ but upon shut down of the system in 1.5 seconds, the velocity of flow is $53.7 \mathrm{~m} / \mathrm{s}$ which is as a result of the high pressure of 37.23 bar attained as shown in Table 4. But as the valve closure rate decreased, there is a decrease in the pressure rise, the final flow velocity, $V_{1}$ also decreased. The remarkable increase in final velocity $V_{1}$ in the pipe at different closure rate can result to several changes in fluid parameters. From the result, the pipe recorded the least final velocity $V_{1}$ of $25.1 \mathrm{~m} / \mathrm{s}$ when the 
Table 1. Fluid data.

\begin{tabular}{cccc}
\hline Fluid density, $\rho\left(\mathrm{Kg} / \mathrm{m}^{3}\right)$ & Flow rate $Q\left(\mathrm{~m}^{3} / \mathrm{s}\right)$ & Pressure $P\left(\mathrm{~N} / \mathrm{m}^{2}\right)$ & Viscosity of fluid $\mu(\mathrm{Kg} / \mathrm{ms})$ \\
\hline 847 & 0.0557 & $25 \times 10^{5}$ & $4.15 \times 10^{-3}$ \\
\hline
\end{tabular}

Table 2. Pipe data.

\begin{tabular}{ccccc}
\hline Pipe length $L(\mathrm{~m})$ & Pipe diameter $d(\mathrm{~m})$ & Wall roughness size $e(\mathrm{~m})$ & $k$-factor $90^{\circ}$ elbow & $k$-factor $45^{\circ}$ elbow \\
\hline 6000 & 0.254 & 0.0002 & 0.9 & 0.4 \\
\hline
\end{tabular}

Table 3. Result of Reynolds number re of the various fluids in varied valve closure time (s).

\begin{tabular}{cccccc}
\hline \multicolumn{2}{r}{ Bonny Light } & \multicolumn{2}{c}{ Bonny medium } & \multicolumn{2}{c}{ Water } \\
\hline Re & $t(\mathrm{~s})$ & Re & $t(\mathrm{~s})$ & Re & $t(\mathrm{~s})$ \\
\hline $2.1 \times 10^{8}$ & 1.5 & $3.5 \times 10^{8}$ & 1.5 & $9.0 \times 10^{8}$ & 1.5 \\
$1.2 \times 10^{8}$ & 2.5 & $2.5 \times 10^{8}$ & 2.5 & $5.3 \times 10^{8}$ & 2.5 \\
$1.0 \times 10^{8}$ & 3 & $1.5 \times 10^{8}$ & 3 & $4.5 \times 10^{8}$ & 3 \\
$8.0 \times 10^{8}$ & 4 & $9.3 \times 10^{8}$ & 4 & $3.3 \times 10^{8}$ & 4 \\
$6.4 \times 10^{8}$ & 5 & $7.2 \times 10^{8}$ & 5 & $2.7 \times 10^{8}$ & 5 \\
\hline
\end{tabular}

Table 4. Pressure and flow rate changes along the pipe in $1.5 \mathrm{~s}$ valve shut down time.

\begin{tabular}{ccccc}
\hline Initial Pressure & Length of Pipe $(\mathrm{m})$ & $\begin{array}{c}\text { Pressure Change } \\
P_{L}\left(\mathrm{~N} / \mathrm{m}^{2}\right)\end{array}$ & $\begin{array}{c}\text { Pressure Difference } \\
P-P_{L}\left(\mathrm{~N} / \mathrm{m}^{2}\right)\end{array}$ & $\begin{array}{c}\text { Flow Rate Change } \\
Q_{L}\left(\mathrm{~m}^{3} / \mathrm{s}\right)\end{array}$ \\
\hline $25 \times 10^{5}$ & 1200 & 744757.644 & 1755214 & $2.93 \mathrm{E}+13$ \\
$25 \times 10^{5}$ & 2400 & 1489515.3 & 1010484.7 & $1.42 \mathrm{E}+13$ \\
$25 \times 10^{5}$ & 3600 & 2234272.9 & 265726.1 & $3.37 \mathrm{E}+12$ \\
$25 \times 10^{5}$ & 4800 & 2979030.5 & -479031.2 & $-5.65 \mathrm{E}+12$ \\
$25 \times 10^{5}$ & 6000 & 3723788.22 & -1223788.2 & $-1.37 \mathrm{E}+13$ \\
\hline
\end{tabular}

Table 5. Pressure and Flow rate changes along the pipe in $2.5 \mathrm{~s}$ valve shut down time.

\begin{tabular}{ccccc}
\hline $\begin{array}{c}\text { Initial Pressure } \\
P\left(\mathrm{~N} / \mathrm{m}^{2}\right)\end{array}$ & Length of Pipe $(\mathrm{m})$ & $\begin{array}{c}\text { Pressure Change } \\
P_{L}\left(\mathrm{~N} / \mathrm{m}^{2}\right)\end{array}$ & $\begin{array}{c}\text { Pressure Difference } \\
P-P_{L}\left(\mathrm{~N} / \mathrm{m}^{2}\right)\end{array}$ & $\begin{array}{c}\text { Flow Rate Change } \\
Q_{L}\left(\mathrm{~m}^{3} / \mathrm{s}\right)\end{array}$ \\
\hline $25 \times 10^{5}$ & 1200 & 68445.4 & 2431554.1 & $2.11 \mathrm{E}+13$ \\
$25 \times 10^{5}$ & 2400 & 1236893.2 & 1263106.8 & $1.31 \mathrm{E}+13$ \\
$25 \times 10^{5}$ & 3600 & 1816345.3 & 683654.7 & $2.18 \mathrm{E}+12$ \\
$25 \times 10^{5}$ & 4800 & 2039443.2 & 460556.8 & $3.16 \mathrm{E}+12$ \\
$25 \times 10^{5}$ & 6000 & 2234053.1 & 265946.9 & $1.13 \mathrm{E}+13$ \\
\hline
\end{tabular}

Table 6. Pressure and Flow rate changes along the pipe in $1.5 \mathrm{~s}$ valve shut down time.

\begin{tabular}{ccccc}
\hline $\begin{array}{c}\text { Initial Pressure } \\
P\left(\mathrm{~N} / \mathrm{m}^{2}\right)\end{array}$ & Length of Pipe $(\mathrm{m})$ & $\begin{array}{c}\text { Pressure Change } \\
P_{L}\left(\mathrm{~N} / \mathrm{m}^{2}\right)\end{array}$ & $\begin{array}{c}\text { Pressure Difference } \\
P-P_{L}\left(\mathrm{~N} / \mathrm{m}^{2}\right)\end{array}$ & $\begin{array}{c}\text { Flow Rate Change } \\
Q_{L}\left(\mathrm{~m}^{3} / \mathrm{s}\right)\end{array}$ \\
\hline $25 \times 10^{5}$ & 1200 & 744757.644 & 1755214 & $2.93 \mathrm{E}+13$ \\
$25 \times 10^{5}$ & 2400 & 1489515.3 & 1010484.7 & $1.42 \mathrm{E}+13$ \\
$25 \times 10^{5}$ & 3600 & 2234272.9 & 265726.1 & $3.37 \mathrm{E}+12$ \\
$25 \times 10^{5}$ & 4800 & 2979030.5 & -479031.2 & $-5.65 \mathrm{E}+12$ \\
$25 \times 10^{5}$ & 6000 & 3723788.22 & -1223788.2 & $-1.37 \mathrm{E}+13$ \\
\hline
\end{tabular}


Table 7. Pressure and Flow rate changes along the pipe in $2.5 \mathrm{~s}$ valve shut down time.

\begin{tabular}{ccccc}
\hline $\begin{array}{c}\text { Initial Pressure } \\
P\left(\mathrm{~N} / \mathrm{m}^{2}\right)\end{array}$ & Length of Pipe $(\mathrm{m})$ & $\begin{array}{c}\text { Pressure Change } \\
P_{L}\left(\mathrm{~N} / \mathrm{m}^{2}\right)\end{array}$ & $\begin{array}{c}\text { Pressure Difference } \\
P-P_{L}\left(\mathrm{~N} / \mathrm{m}^{2}\right)\end{array}$ & $\begin{array}{c}\text { Flow Rate Change } \\
Q_{L}\left(\mathrm{~m}^{3} / \mathrm{s}\right)\end{array}$ \\
\hline $25 \times 10^{5}$ & 1200 & 68445.4 & 2431554.1 & $2.11 \mathrm{E}+13$ \\
$25 \times 10^{5}$ & 2400 & 1236893.2 & 1263106.8 & $1.31 \mathrm{E}+13$ \\
$25 \times 10^{5}$ & 3600 & 1816345.3 & 683654.7 & $2.18 \mathrm{E}+12$ \\
$25 \times 10^{5}$ & 4800 & 2039443.2 & 460556.8 & $3.16 \mathrm{E}+12$ \\
$25 \times 10^{5}$ & 6000 & 2234053.1 & 265946.9 & $1.13 \mathrm{E}+13$ \\
\hline
\end{tabular}

Table 8. Pressure and Flow rate changes along the pipe in $3 \mathrm{~s}$ valve shut down time.

\begin{tabular}{ccccc}
\hline $\begin{array}{c}\text { Initial Pressure } \\
P\left(\mathrm{~N} / \mathrm{m}^{2}\right)\end{array}$ & Length of Pipe $(\mathrm{m})$ & $\begin{array}{c}\text { Pressure Change } \\
P_{L}\left(\mathrm{~N} / \mathrm{m}^{2}\right)\end{array}$ & $\begin{array}{c}\text { Pressure Difference } \\
P-P_{L}\left(\mathrm{~N} / \mathrm{m}^{2}\right)\end{array}$ & $\begin{array}{c}\text { Flow Rate Change } \\
Q_{L}\left(\mathrm{~m}^{3} / \mathrm{s}\right)\end{array}$ \\
\hline $25 \times 10^{5}$ & 1200 & 522289.8 & 2447710.2 & $2.41 \mathrm{E}+12$ \\
$25 \times 10^{5}$ & 2400 & 1144993.5 & 1355006.5 & $3.66 \mathrm{E}+13$ \\
$25 \times 10^{5}$ & 3600 & 1511922.4 & 988077.6 & $2.00 \mathrm{E}+12$ \\
$25 \times 10^{5}$ & 4800 & 1623344.9 & 876655.1 & $2.16 \mathrm{E}+13$ \\
$25 \times 10^{5}$ & 6000 & 1861234.3 & 688765.7 & $1.33 \mathrm{E}+13$ \\
\hline
\end{tabular}

Table 9. Pressure and Flow rate changes along the pipe in $4 \mathrm{~s}$ valve shut down time.

\begin{tabular}{ccccc}
\hline $\begin{array}{c}\text { Initial Pressure } \\
P\left(\mathrm{~N} / \mathrm{m}^{2}\right)\end{array}$ & Length of Pipe $(\mathrm{m})$ & $\begin{array}{c}\text { Pressure Change } \\
P_{L}\left(\mathrm{~N} / \mathrm{m}^{2}\right)\end{array}$ & $\begin{array}{c}\text { Pressure Difference } \\
P-P_{L}\left(\mathrm{~N} / \mathrm{m}^{2}\right)\end{array}$ & $\begin{array}{c}\text { Flow Rate Change } \\
Q_{L}\left(\mathrm{~m}^{3} / \mathrm{s}\right)\end{array}$ \\
\hline $25 \times 10^{5}$ & 1200 & 40138.7 & 2459861.3 & $1.11 \mathrm{E}+12$ \\
$25 \times 10^{5}$ & 2400 & 924778.1 & 1575221.9 & $2.66 \mathrm{E}+13$ \\
$25 \times 10^{5}$ & 3600 & 1023496.3 & 1496503.7 & $1.56 \mathrm{E}+12$ \\
$25 \times 10^{5}$ & 4800 & 1122496.4 & 1377503.6 & $2.37 \mathrm{E}+13$ \\
$25 \times 10^{5}$ & 6000 & 1396445.3 & 1103554.7 & $3.49 \mathrm{E}+11$ \\
\hline
\end{tabular}

Table 10. Pressure and Flow rate changes along the pipe in $5 \mathrm{~s}$ valve shut down time.

\begin{tabular}{ccccc}
\hline $\begin{array}{c}\text { Initial Pressure } \\
P\left(\mathrm{~N} / \mathrm{m}^{2}\right)\end{array}$ & Length of Pipe $(\mathrm{m})$ & $\begin{array}{c}\text { Pressure Change } \\
P_{L}\left(\mathrm{~N} / \mathrm{m}^{2}\right)\end{array}$ & $\begin{array}{c}\text { Pressure Difference } \\
P-P_{L}\left(\mathrm{~N} / \mathrm{m}^{2}\right)\end{array}$ & $\begin{array}{c}\text { Flow Rate Change } \\
Q_{L}\left(\mathrm{~m}^{3} / \mathrm{s}\right)\end{array}$ \\
\hline $25 \times 10^{5}$ & 1200 & 41289.4 & 2458710.6 & $2.0 \mathrm{E}+13$ \\
$25 \times 10^{5}$ & 2400 & 712594.6 & 1787405.4 & $2.11 \mathrm{E}+12$ \\
$25 \times 10^{5}$ & 3600 & 946438.7 & 1553561.3 & $3.08 \mathrm{E}+12$ \\
$25 \times 10^{5}$ & 4800 & 1247891.3 & 1252108.7 & $3.44 \mathrm{E}+13$ \\
$25 \times 10^{5}$ & 6000 & 1355663.2 & 1144336.8 & $1.0 \mathrm{E}+13$ \\
\hline
\end{tabular}

Table 11. Hydraulic force $F(\mathrm{KN})$ result at varied valve closure time $t(\mathrm{~s})$.

\begin{tabular}{cccc}
\hline Valve closure time, $t(\mathrm{~s})$ & Force, $F(45 \mathrm{deg})(\mathrm{KN})$ & Force, $F(90 \mathrm{deg}(\mathrm{KN})$ & $V_{1}(\mathrm{~m} / \mathrm{s})$ \\
\hline 1.5 & 18291.4 & 34651 & 53.7 \\
2.5 & 6544.1 & 12552 & 25.1 \\
3 & 4276.4 & 8552.7 & 38.9 \\
4 & 2509.9 & 4670.9 & 51.2 \\
5 & 1758.8 & 2906.5 & 57.2 \\
\hline
\end{tabular}


Table 12. Stagnation values at varied closure time (Bonny light).

\begin{tabular}{ccccc}
\hline Valve closure time, $t(\mathrm{~s})$ & $V(\mathrm{~m} / \mathrm{s})$ & $T_{o}(\mathrm{k})$ & $P_{O}(\mathrm{~m} / \mathrm{s})$ & $H_{O}(\mathrm{KJ} / \mathrm{kg})$ \\
\hline 1.5 & 53.7 & 2174.4 & 12.2 & 1515.9 \\
2.5 & 25.1 & 834.6 & 2.7 & 389.11 \\
3 & 38.9 & 1359.6 & 6.4 & 830.7 \\
4 & 51.0 & 2006.4 & 11.0 & 1374.6 \\
5 & 57.2 & 2405.2 & 13.0 & 1710.0 \\
\hline
\end{tabular}

valve closed in 2.5 seconds as shown in Table 11. This velocity should be adjudged to the best valve closure rate suitable to maintain forty one thousand barrels per day capacity $(0.0557 \mathrm{~m} / \mathrm{s})$ of the system.

But on reduction of the flow rate (volume) and the valve maintains 2.5 seconds closure time, the velocity dropped considerably which indicates that the pipeline operates at high flow rate initially. The modeling shows that for any volume flow rate, $Q \mathrm{~m}^{3} / \mathrm{s}$ there is a valve closure time suitable for the pipeline in which pressure changes can be tolerated even at surge suppression device failure. The capacity of the pipeline under investigation is 41,000 barrels/day $\left(0.0557 \mathrm{~m}^{3} / \mathrm{s}\right)$ operating at 25 bar initial pressure and installed emergency reliefcoupling valve closure time of 1.5 seconds, upon the shutdown of the system by the valve in response to an emergency, the pressure attained at $6000 \mathrm{~m}$ length of pipe is 37.23 bar as against 25 bar operating pressure despite the pressure loss in the flow. This pressure attained on closure at 1.5 seconds is very high for the system and leads the system to surge. Consider the result in Table 11, the flow velocity is $1.12 \mathrm{~m} / \mathrm{s}$ but upon shut down of the system in 1.5 seconds, the velocity of flow is $53.7 \mathrm{~m} / \mathrm{s}$ which is as a result of the high pressure of 37.23 bar attained as shown in Table 4. But as the valve closure rate decreased, there is a decrease in the pressure rise, the final flow velocity, $V_{1}$ also decreased. The remarkable increase in final velocity $V_{1}$ in the pipe at different closure rate can result to several changes in fluid parameters. From the result, the pipe recorded the least final velocity $V_{1}$ of $25.1 \mathrm{~m} / \mathrm{s}$ when the valve closed in 2.5 seconds as shown in Table 11 . This velocity should be adjudged to the best valve closure rate suitable to maintain forty one thousand barrels per day capacity $(0.0557 \mathrm{~m} / \mathrm{s})$ of the system. At 4.0 seconds, it experienced a gradual fall in the hydraulic force. It can be concluded that hydraulic force propagation decreases with an increase in valve closure time. The same trend followed in the $45^{\circ}$ elbow, though the highest hydraulic force is $18,000 \mathrm{KN}$ when the valve closed in 1.1 seconds whereas the $90^{\circ}$ elbow has the highest hydraulic force value of $37,000 \mathrm{KN}$ when the valve closed in 1.5 seconds. It can also be deduced that hydraulic force propagation depends on the type of elbow used in the pipeline. Therefore, the research does not advice against the use of $90^{\circ}$ elbows since its usage depends on the slope of the soil. Though it is suggested that instead of using more $90^{\circ}$ elbow in pipeline transmission, effort should be made to use more $45^{\circ}$ elbow.

Consider what happens if the inlet flow rate (volume) was increased to $0.06109 \mathrm{~m} / \mathrm{s}$ and the valve set to close in 2.5 seconds. The maximum pressure rise was 24.2 bar and a decrease in flow rate of $0.04752 \mathrm{~m}^{3} / \mathrm{s}$, the maximum pressure rise was 18.8 bar. It shows that at an increased flow rate, at time t, the pressure change would be increasing capable of surge pressure. But at a decreased flow rate at time t, the pressure change would be decreasing capable of falling below vapor pressure of the crude oil. Hence, modeling the closure time $t$ at a given flow rate is quite necessary for satisfactory result. As stated earlier, there is always a closure time limit for the valve over which pressure changes can be tolerated owing to level of pressure losses in the system. This is particularly shown in Table 4 where a flow rate of $0.0557 \mathrm{~m}^{3} / \mathrm{s}$ of crude oil was maintained at different valve closure time. Hence, the analysis shows that the limit between 2.5 seconds to 3.0 seconds valve closure rate can be tolerated. This fact has not been considered previously owing to over-dependence on surge suppression devices which on its own has shown high failure rate. The failure of these devices has led to adverse environmental anomalies like spillage, excessive cost of maintenance of pipeline and pipe machines.

\section{Conclusion}

Results of the analysis identified valve operation as a major cause of surge propagation. Surge is a potentially damaging flow instability that limits the flow operation of pipe machines. The rate at which the emergency relief-coupling valve (ERV) closes is significant in pressure surge propagation. At faster closure rate, the pressure 
of the system rises such that can destroy the pipeline mechanically, while at slower valve closure rate, there is high tendency of vacuum separation in the system due to a remarkable fall in the pressure of the system. Hence, there is always a limit of valve closure time suitable for any pipeline at any given flow rate. Hydraulic forces propagation decreases with increasing emergency relief-coupling valve (ERV) closure time. Leakages from fittings (bends) are mostly due to the propagation of hydraulic forces arising from valve closure. Pressure change in a pipeline installed with emergency relief-coupling valve increases with, fluid density, flow rate (volume) pipe length and decreases with pipe diameter and valve closure rate upon shut down. The fluid Reynolds number decreases with increasing emergency relief-coupling valve closure rate. As a result of the movement of the elbow, created by the shutdown of ERV at time t, the joint will become weaker and in extreme cases, they may come apart, hence enable air to be trapped into the system. An emergency relief-coupling valve (ERV) should be installed in a system to guard against storm; hence proper design of its operation should be considered before installation.

\section{References}

[1] Stone, G.D. (2013) Avoiding Pressure Surge Damage in Pipeline Systems. SE Asia, Feb Publishers, Australia.

[2] Voith Industrial Services (2014) Pressure Surges: Analysis and Prevention. www.voith.com

[3] Lebele-Alawa, B.T. and Oparadike, F.E. (2011) Analysis of the Effects of Valve Propagated Pressure Surge on Pipe Flow. Engineering, 3, 1098-1101. http://dx.doi.org/10.4236/eng.2011.311137

[4] Cla-Val, A. (2013) Surge Analysis and Control. www.cal-val.com

[5] Jung, B.S., Boulos, P.F. and Don, J.W. (2009) Effect of Pressure-Sensitive Demand on Surge Analysis. Journal of American Water Works Association, (AWWA), 101, 103-111.

[6] Sunrise Systems Customer Education Training Manual (2008) Modeling Pipeline and Utility Systems Using Pipenet Vision. www.sunrise-sys.com

[7] Rajput, R.K. (2004) A Textbook of Fluid Mechanics and Hydraulic Machines. S. Chand and Company Ltd., New Delhi.

[8] Eastop, T.D. and McConkey, A. (1993) Applied Thermodynamics for Engineering Technologists. Prentice Hall, Singapore.

[9] Lebele-Alawa, B.T. (2007) Effects of Compressor-Blade Profile Change on Gas-Turbine Performance. Ph.D. Thesis, Rivers State University of Science and Technology, Port Harcourt. 


\section{Notations}

A Area of pipe, $\mathrm{m}^{2}$

C Shock wave speed, $\mathrm{m} / \mathrm{s}$

$C_{1} \quad$ Pipe distensibility (restrain factor)

$C_{p} \quad$ Specific heat of fluid at constant pressure, $\mathrm{kJ} / \mathrm{kgK}$

$d \quad$ Diameter of pipe, $\mathrm{m}$

$E_{y} \quad$ Young's Modulus for the pipe material, $\mathrm{N} / \mathrm{m}^{2}$

ERV Emergency relief coupling valve

$g$ Acceleration due to gravity, $\mathrm{m} / \mathrm{s}^{2}$

$H_{f} \quad$ Head loss due to friction, $\mathrm{m}$

$K \quad$ Fluid bulk Modulus, $\mathrm{N} / \mathrm{m}^{2}$

$L \quad$ Length of pipe, $m$

$\dot{\mathrm{m}} \quad$ Mass flow rate, $\mathrm{Kg} / \mathrm{s}$

NSV Normal shut-off valve

$P \quad$ Pipe pressure, $\mathrm{N} / \mathrm{m}^{2}$

$P_{o} \quad$ Stagnation pressure, $\mathrm{N} / \mathrm{m}^{2}$

Re Reynolds number

$t$ Period (time), $\mathrm{s}$

$t_{h} \quad$ Pipe thickness, $\mathrm{m}$

$T$ Temperature, $\mathrm{K}$

$T_{o} \quad$ Stagnation temperature, $\mathrm{K}$

$V \quad$ Flow velocity, $\mathrm{m} / \mathrm{s}$

$e \quad$ Pipe Roughness Size

$F$ Force, $\mathrm{N}$

$F_{x} \quad$ Force in direction of $x, \mathrm{~N}$

$F_{y} \quad$ Force in direction of $y, \mathrm{~N}$

$f$ Pipe Friction Factor

$H \quad$ Total Head Loss m

$k \quad$ Fitting Loss Coefficient

$K_{1} \quad$ Bulk Modulus of Fluid

Q Volumetric Flow Rate, $\mathrm{m}^{3} / \mathrm{s}$

$Q_{L} \quad$ Change in Flow Rate, $\mathrm{m}^{3} / \mathrm{s}$

$R_{L} \quad$ Pressure ratio

$t \quad$ Time, $\mathrm{s}$

$t_{n} \quad$ Pipe thickness, $\mathrm{m}$

\section{Greek Letters}

$\rho \quad$ Density of the Fluid, $\mathrm{kg} / \mathrm{m}^{3}$

$\mu \quad$ Dynamic Viscosity of Fluid, $\mathrm{kg} / \mathrm{m} / \mathrm{s}$

$\tau \quad$ Wall Shear Stress, $\mathrm{N} / \mathrm{m}^{2}$

\section{Suffixes}

1. Initial state

2. Final state 